\title{
Biochemical studies of rice phytoalexins
}

\author{
Osamu KodAMA* \\ 児玉 治*：イネファイトアレキシンの生化学的研究
}

\section{Introduction}

Although, it is possible to control rice blast disease using fungicides, rice blast disease remains a difficult problem in Asian paddy fields. Recently, many people have demanded a decrease in the use of pesticides because of their adverse affects to the environment. Therefore, studies on the defense mechanism of rice plant against rice blast disease, especially rice phytoalexin have become very important. Phytoalexins are low-molecular weight antifungal compounds which are synthesized and accumulated in plant cells after exposure to plant pathogenic fungi. Phytoalexin production is thought to be a plant defense mechanism.

In our studies of rice plant phytoalexins, we have isolated and identified the diterpene phytoalexins, oryzalexins $A \sim F^{1-5}$, oryzalexin $S^{6}$, and the flavanone phytoalexin, Sakuranetin ${ }^{7}$, in the foliar parts of rice plants infected with blast fungus, Pyricularia oryzae and UV-irradiated rice leaves. Additionally momilactones $\mathrm{A}$ and $\mathrm{B}$ are also produced in UV-irradiated rice leaves or blast-infected rdce leaves pretreated with WL-28325 (2,2-dichloro-3,3-dimmenthylcyclopropane

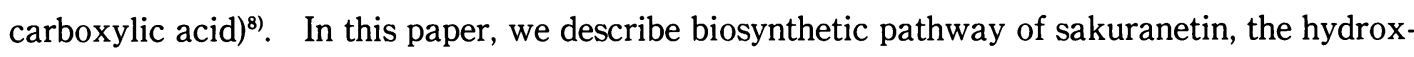
ylation of the nonantifungal precursor, ent-isopimara-8 (14),15-diene- $3 \beta$-ol to produce oryzalexins $\mathrm{D}$ and $\mathrm{E}$, and role of jasmonic acid on rice phytoalexin production.

\section{Biosynthesis of oryzalexins D and E}

Oryzalexins are considered to be synthesized from mevalonic acid through geranylgeranyl pyrophoshate. Recently, Wickham and West found ent-isopimara 8(14), 15-diene in cell-free extracts from UV-irradiated rice leaves and suggested that the substance was the precursor of oryzalexins?.

Since the oryzalexins are oxygenated, it is speculated that oryzalexins are synthesized by the hydroxylation of the oxygen-free precursor, ent-isopimara-8(14),15-diene. However, hydroxylation steps in the biosynthetic pathways of rice diterpene phytoalexins phytoalexins have not been demonstrated. Therefore, we undertook the isolation of hydroxylated precursors of rice diterpene phytoalexins to clarify further the biosynthetic pathway of oryzalexins.

As a result, we found ent-isopimara-8(14),15-diene- $3 \beta$-ol in the $70 \%$ methanol extracts of UV-irradiated rice leaves ${ }^{12}$. Since $e n t$-isopimara-8(14),15-diene-3 $\beta$-ol exhibited no antifungal

\footnotetext{
* Laboratory of Bioorganic and Pesticide Chemisty, School of Agriculture, Ibaraki University, Ami, Ibaraki 300-03, Japan

茨城大学農学部（テ300-03 茨城県稲敷郡阿見町中央 3-21-1）
} 

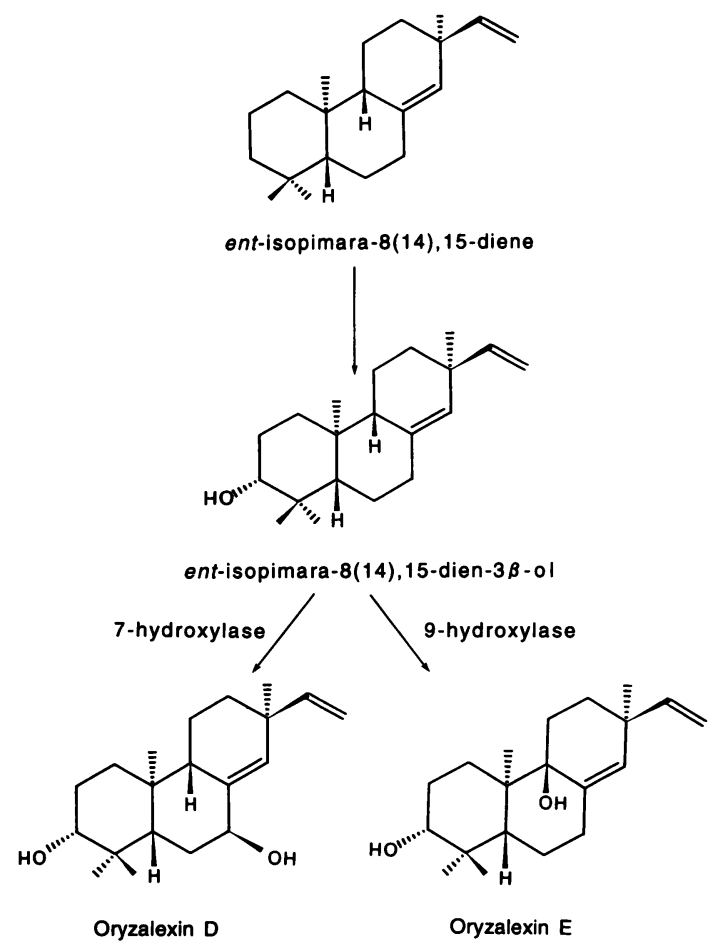

Fig. 1 Biosynthetic pathway for oryzalexins D and E.

activity against $P$. oryzae and the introduction of two hydroxy groups, especially hydroxylation at the 7- or 9-position in ent-isopimara-8(14),15-diene-3 $\beta$-ol, are very important for the antifungal activity and self-defense mechanism of rice plants. Biosynthetic pathway for oryzalexins $D$ and $\mathrm{E}$ are shown in Fig. 1. Some properties of the enzymes involved in the hydroxylation of ent-isopimara-8(14),15-diene-3 $\beta$-ol to form oryzalexin $\mathrm{D}$ and $\mathrm{E}$ have been established. These activities require oxygen and reduced coenzyme. NADPH was the preferential electron donor for oryzalexins $\mathrm{D}$ and $\mathrm{E}$ biosynthesis. Hydroxylase activities were inhibited by piperonyl butoxide, SKF-525A, paclobutrazol, and carbon monoxide. The inhibitions with carbon monoxide were reversed by white light. The features mentioned above are common to cytochrome P-450 systems.

Therefore, it is strongly suggested that the terminal enzymes of oryzalexins $\mathrm{D}$ and $\mathrm{E}$ biosynthesis from ent-isopimara-8(14),15-diene-3 $\beta$-ol are cytochrome P450-dependent monooxygenases. Thus, cytochrome $\mathrm{P} 450$ s play an important role in plant defense mechanism and also act as important steps in rice phytoalexin biosynthesis.

\section{Biosynthesis of sakuranetin}

Sakuranetin was first isolated from the bark of cherry tree as the aglycon of sakuranin in 1908 by Asahina ${ }^{11)}$. Recently, we isolated sakuranetin as a rice phytoalexin from UV-irradiated and blast-infected rice leaves ${ }^{7}$. The application of $1 \mathrm{mM} \mathrm{CuCl}_{2}$ to the press-injured spot of rice 


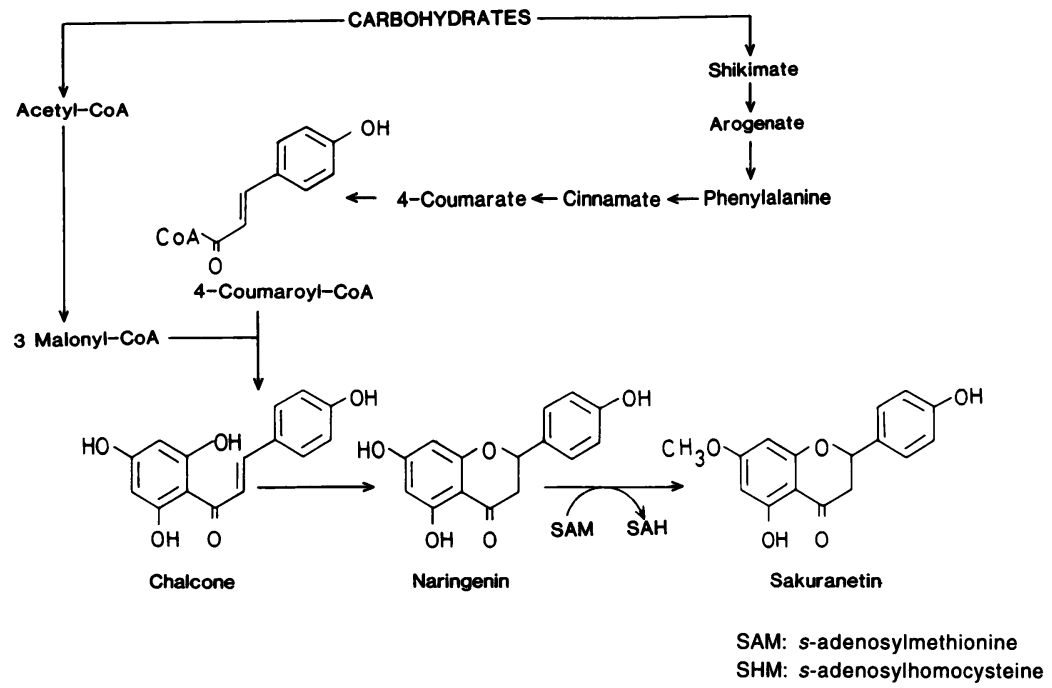

Fig. 2 Biosynthetic pathway for sakuranetin.

leaves also induced the production of sakuranetin. Therefore, we applied $\left[{ }^{14} \mathrm{C}\right]$ phenylalanine or $\left[{ }^{14} \mathrm{C}\right] \mathrm{s}$-adenosylmethionine together with $\mathrm{CuCl}_{2}$ to clarify the biosynthetic pathway of sakuranetin. In the presence of $\mathrm{CuCl}_{2},\left[{ }^{14} \mathrm{C}\right]$ phenylalanine or $\left[{ }^{14} \mathrm{C}\right] \mathrm{s}$-adenosylmethionine incorporated into the sakuranetin fraction effectively. In contrast, control experiment using distilled water instead of $\mathrm{CuCl}_{2}$ as a droplet, this incorporation was not observed. Crude enzyme solution obtained from UV-irradiated rice leaves catalyzed the methylation of position 7 of naringenin to produce sakuranetin using $s$-adenosylymethionine as a methyl donor. These results strongly suggest that the biosynthetic pathway of sakuranetin follows the scheme shown as Fig. 2 .

The $\mathrm{ED}_{50}$ of sakuranetin against spore gemination of $P$. oryzae was approximately $15 \mathrm{ppm}$. On the other hand, naringenin (1,7,4'-trihydroxylflavanone), which is a precursor of sakuranetin, scarcely inhibited spore germination at concentrations up to $50 \mathrm{ppm}$. This difference may be dependent on the difference in hydrophobicity following methylation of the hydroxyl group at position 7 of naringenin. Methylation enzme is very important for self-defense mechanism of rice plant. Purification of the enzyme catalyzing the methylation of naringenin from UV irradiated rice leaves is now in progress.

\section{Role of Jasmonic acid for production of rice phytoalexins}

Phytoalexin production in the rice plant is not only triggered by invasion of $P$. oryzae, but also by treatment with UV-irradiation ${ }^{13)}$ and salts of heavy metals like $\mathrm{CuCl}_{2}{ }^{12}$. It seems reasonable that the same biochemical reaction accounts for the production of phytoalexins in rice leaves after invasion by $P$. oryzae or an elicitor treatment. Previous studies have demonstrated the induction of oxygenated fatty acids after biotic or abiotic elicitor treatment ${ }^{14)}$.

The amounts of sakuranetin and momilactone $\mathrm{A}$ in and around the press injured spots of rice leaves after application of jasmonic acid, the metabolite of fatty acid, to the spots was investigat- 


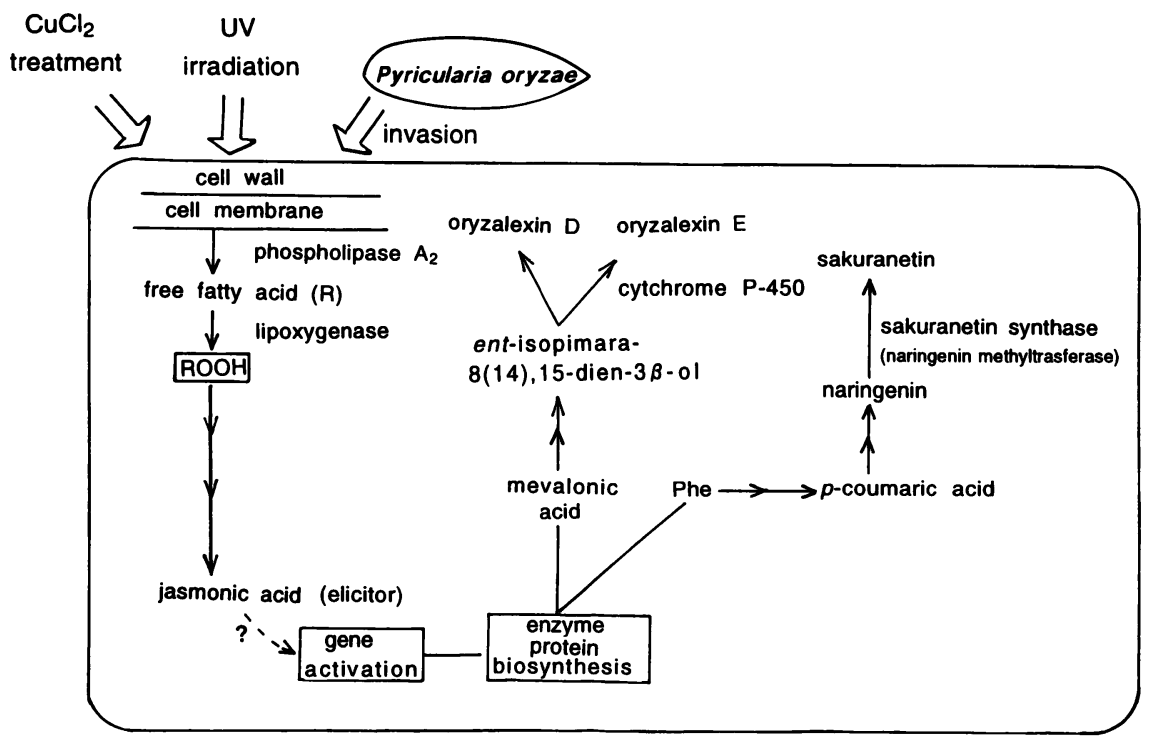

Fig. 3 Rice plant defence signaling for production of phytoalexins.

ed. A dramatic increase in the amounts of rice phytoalexins sakuranetin and momilactone A has been observed after treatment of rice leaves with jasmonic acid. The enzymes phospholipase $A_{2}$ and lipoxygenase are involved with release of fatty acids from the phospholipids of cell membranes,and with the consequent production of jasmonic acid. Increases of phospholipase $\mathrm{A}_{2}$ and lipoxygenase activity after inoculating with $P$. oryzae or elicitation with $\mathrm{CuCl}_{2}$ were observed ${ }^{14)}$. Quinacrine and nordihydroguaiaretic acid are known to be phospholipase $\mathrm{A}_{2}$ inhibitor and lipoxygenase inhibitor, respectively. Treatments with $50 \mathrm{ppm}$ of the enzyme inhibitors in the presence of jasmonic acid had no effect on production of either of the two phytoalexins sakuranetin and momilactone A. However, treatments with $50 \mathrm{ppm}$ of the above inhibitors in the presence of $\mathrm{CuCl}_{2}$ as the elicitor resulted in a dramatic decrease in the amounts of sakuranetin and momilactone A produced.

In view of a previously presented hypothesis ${ }^{15)}$ and the results here, we propose that JA and/ or its metabolites acts as the terminal endogenous elicitor molecule in the signal transduction chain effecting gene activation, ultimately leading to rice phytoalexin production (Fig. 3).

Acknowledgements I would like to thank Professors. Ueno, Y. and Adachi, Y. for providing me the opportunity to introduce my research work at the 41th meeting of the Japanese Association of Mycotoxicology.

\section{References}

1) Akatsuka, T., Kodama, O., Kato, H., Kono, Y., Takeuchi, S.: Agric. Biol. Chem., 47, 445 (1983).

2) Kono, Y., Takeuchi, S., Kodama, O., Kkatsuka, T. : Agric. Biol. Chem. : Agric Biol. Chem., 48, 253 (1984).

3) Sekido, H., ERndo, T., Suga, R., KOdama, O., Akatsuka, T., Kono, Y., Takeuchi, S. : J. Pesticide Sci., 11, 369 (1986).

4) Kato, H., Kodama, O., Akatsuka, T. : Phytochemistry, 33, 79 (1993).

5) Kato, H., Kodama, O., Akatsuka, T. : Phytochemistry, 36, 299 (1994).

6) Tamogami, S., Mitani, M., Kodama, O., Akatsuka, T.: Tetrahedron, 49, 2025 (1993). 
7) Kodama, O., Miyakawa, J., Akatsuwa, S.: Phytochemistry, 31, 3807 (1992).

8) Cartwright, D. W., Langcake, P., Pryce, R. J., Ride, J. P.: Phytochemistry, 20, 535 (1981).

9) Wickham, K. A., West, C. A. : Arch. Biochem. Biophys., 293, 320 (1992).

10) Kato, H., Kodama, O., Akatsuka, T.: Arch. Biochem. Biophys., 316, 707 (1995).

11) Asahina, Y.: Arch. Pham., 246, 259 (1908).

12) Kodama, O., Yamada, A., Takemoto, T.: J. Pestcide Sci., 13, 615 (1988).

13) Kodama, O., Suzuki, T., Miyakawa, J. Akatsuka, T.: Agric. Biol. Chem., 52, 2469 (1988).

14) LI, W. X., Kodama, O., Akatsuka, T.: Agric. Biol. Chem., 55, 1041 (1991).

15) Farmer, E. E., Johnson, R. R., Ryan, C. A. : Plant Physiol., 98, 995 (1992). 